CLINICAL STUDY

\title{
Resistin is associated with biomarkers of inflammation while total and high-molecular weight adiponectin are associated with biomarkers of inflammation, insulin resistance, and endothelial function
}

\author{
Jessica L Fargnoli ${ }^{1}$, Qi Sun ${ }^{2}$, Deanna Olenczuk ${ }^{1}$, Lu Qi ${ }^{2}$, Ying Zhu ${ }^{1}$, Frank B Hu ${ }^{2,3,4}$ and Christos S Mantzoros ${ }^{1}$ \\ ${ }^{1}$ Division of Endocrinology, Diabetes, and Metabolism, Department of Medicine, Harvard Medical School, Beth Israel Deaconess Medical Center, 330 \\ Brookline Avenue, ST816, Boston, Massachusetts 02115, USA, Departments of ${ }^{2}$ Nutrition and ${ }^{3}$ Epidemiology, Harvard School of Public Health, Boston, \\ Massachusetts, USA and ${ }^{4}$ Channing Laboratory, Department of Medicine, Harvard Medical School, Brigham and Women's Hospital, Boston, \\ Massachusetts, USA
}

(Correspondence should be addressed to C S Mantzoros; Email: cmantzor@bidmc.harvard.edu)

\begin{abstract}
Objective: Adiponectin and resistin have been linked to inflammation, endothelial dysfunction, and/or insulin secretion or resistance. It remains to be elucidated which of these adipokines is associated primarily with biomarkers of all or only some of these categories, i.e. biomarkers of inflammation, endothelial dysfunction, and/or insulin secretion or insulinemia.

Design and methods: We studied 1065 healthy women, Nurses' Health Study participants, who provided blood samples in 1989-1990. A cross-sectional analysis was conducted to assess the relationships between total and high-molecular weight (HMW) adiponectin and resistin with inflammatory markers and biomarkers of endothelial dysfunction, insulin secretion, and insulinemia.

Results: Resistin was positively associated with the inflammatory markers soluble tumour necrosis factor- $\alpha$ receptor II and interleukin- 6 but not with any biomarkers of endothelial function, glycemia, insulinemia, or markers of insulin secretion after multivariate adjustment for age and body mass index (BMI). In both crude and multivariate analyses, total adiponectin was inversely associated with insulin, proinsulin, C-peptide, HbA1c, sE-selectin, and C-reactive protein (CRP) levels. HMW adiponectin was inversely associated with circulating insulin, proinsulin, C-peptide, HbAlc, sE-selectin, and CRP concentrations, even after adjustment for age, BMI, lifestyle factors, exercise, the use of medications as well as the other biomarkers of interest. Total and HMW adiponectin demonstrated negative associations with soluble intercellular adhesion molecule-1, which became nonsignificant after adjustment for confounders, whereas positive associations between soluble vascular cell adhesion molecule-1 and total adiponectin became significant only after multivariate adjustment.

Conclusions: Total and HMW adiponectin are inversely associated with markers of insulin secretion/insulinemia, endothelial function, and inflammation. Resistin is positively associated only with markers of inflammation.
\end{abstract}

European Journal of Endocrinology 162 281-288

\section{Introduction}

The discovery of leptin, the prototypical adipose tissue-secreted adipokine, in the mid-90s altered our understanding of adipose tissue from that of an inert storage organ to that of an active endocrine organ (1). Adipose tissue secretes several adipokines, most of them, such as tumour necrosis factor- $\alpha$ (TNF- $\alpha$ ) and interleukin-6 (IL-6), negatively affecting insulin resistance and others, such as adiponectin, having a beneficial effect. Adiponectin is a metabolically active adipokine, which is inversely associated with obesity, insulin resistance, and atherosclerosis (2-4). Prospective studies have shown that higher plasma adiponectin concentrations are associated with decreased risk of type 2 diabetes mellitus (5), cardiovascular disease (CVD) in men with type 2 diabetes mellitus (6), and myocardial infarction in men with or without diabetes (7). Adiponectin is present in plasma in three forms: a trimer, a hexamer, and a high-molecular weight (HMW) form, which has been proposed to be the most active adiponectin form (8). Total adiponectin levels have previously been shown to be associated with better glycemic control and reduced inflammation in type 2 diabetic women from the Nurses' Health Study (9), but associations of adiponectin with biomarkers of inflammation, such as TNF- $\alpha$ and IL-6, endothelial dysfunction, such as soluble intercellular adhesion 
molecule-1 and soluble vascular cell adhesion molecule-1 (sICAM-1 and sVCAM-1), and insulin resistance and secretion in healthy women have yet to be examined. Moreover, relationships between HMW adiponectin and biomarkers of inflammation, endothelial dysfunction, and insulin resistance have not been previously explored in either healthy or diabetic women.

Resistin was originally discovered as an adipokine, which was found to be elevated in the diet-induced obese mouse model and was proposed to induce insulin resistance or impaired hepatic sensitivity to insulin (10). However, data in humans remain controversial. In contrast to mice, resistin in humans is expressed in lower levels in adipocytes but at relatively higher levels in circulating blood monocytes (11). Several studies have failed to detect increased serum resistin levels in obese or insulin-resistant subjects (12). Although its role in insulin resistance has been challenged, it has been subsequently proposed that resistin may promote endothelial cell activation and upregulate several adhesion molecules and cytokines $(13,14)$. Since both inflammation and insulin resistance play critical roles in the development of atherosclerosis (15), associations with biomarkers of inflammation and/or endothelial function would imply that resistin could possibly be directly or indirectly related to CVD. Associations between resistin and biomarkers of inflammation, endothelial dysfunction, and insulin resistance and secretion have not been previously explored in healthy women.

In view of these data, we utilized a large sample of healthy nondiabetic women studied in the context of the Nurses' Health Study to assess whether circulating total and HMW adiponectin and resistin levels are associated with biomarkers of insulin resistance or insulin secretion as well as biomarkers of inflammation and endothelial function, independently of known risk factors. Thus, we analyzed the cross-sectional associations of total and HMW adiponectin and resistin with biomarkers of inflammation, endothelial dysfunction, and insulin resistance.

\section{Methods}

\section{Study population}

The Nurses' Health Study was initiated in 1976 with the enrollment of 121700 USA nurses, aged 30-55 years at baseline. This cohort study involves biennially mailed questionnaires related to lifestyle factors and health outcomes. Between 1989 and 1990, 32826 study participants provided blood samples by overnight courier. Study participants of the current analysis were a subset of the prospective Nurses' Health Study, all of whom were healthy at baseline. We identified and confirmed all women who developed type 2 diabetes over a 12-year period of follow-up, as well as an equal number of women who were diabetes-free at baseline and never developed diabetes during this 12-year period of follow-up. All subjects were free of diabetes and CVD at blood draw. In order to keep sample size constant throughout models in multivariate adjustment, we excluded women who had missing data for biomarkers of interest, including plasma total and HMW adiponectin, resistin, soluble TNF- $\alpha$ receptor receptor II (sTNF- $\alpha$ RII), C-reactive protein (CRP), IL-6, sICAM-1, sVCAM-1, sE-selectin, and ferritin. We further excluded women with missing data on confounders (age, body mass index (BMI), smoking status, alcohol intake, physical activity, fasting status, postmenopausal status, postmenopausal hormone use, aspirin use, history of hypertension, or hypercholesterolemia). After such exclusions, 576 healthy women who developed type 2 diabetes later in life and 489 healthy women who never developed type 2 diabetes were available for analysis. First, we analyzed data from all 1065 subjects with adjustment for an indicator variable indicating development of diabetes later in life. An additional, independent analysis was conducted in the subset of 489 of these women who never developed type 2 diabetes mellitus using established criteria (16). The study was approved by the Institutional Review Board (IRB) of Brigham and Women's Hospital and the biochemical measures by the IRB of Beth Israel Deaconess Medical Center, both in Boston, MA, USA.

\section{Blood collection and processing}

Blood samples were collected between 1989 and 1990 as previously described (16). Briefly, a phlebotomy kit was sent to all the women who agreed to provide blood samples. The samples were returned by overnight mail in a frozen water bottle, processed on arrival, and stored in liquid nitrogen $\left(-130{ }^{\circ} \mathrm{C}\right.$ or less) until time of analysis. The samples were analyzed in a random order, and laboratory personnel were blinded to the study hypothesis. All assays for each analyte run for this study for the first time (i.e., total adiponectin, HMW adiponectin, and resistin) were run in one run. All assays have been used and described in detail elsewhere $(6,7,9,12$, 17-19). Briefly, total adiponectin concentration was measured using RIA (Linco Research, Inc., St Charles, MO, USA), which has a sensitivity of $2 \mu \mathrm{g} / \mathrm{ml}$ and intraassay coefficient of variation (CV) of $1.8-6.2 \%$. Serum HMW adiponectin levels were determined by ELISA (Millipore, St Charles, MO, USA) with a sensitivity of $0.5 \mathrm{ng} / \mathrm{ml}$. Resistin was assayed by ELISA (Linco Research, Inc). The minimum detectable range of this assay is $0.16 \mathrm{ng} / \mathrm{ml}$ for a sample size of $10 \mu \mathrm{l}$ (diluted $1: 10$ ); intra-assay $\mathrm{CV} \%, 3.2-7.0 \%$. Intra-assay precision was determined using four samples of known concentration tested ten times on one plate. Assays for sTNF- $\alpha$ RII, CRP, IL-6, sICAM-1, sVCAM-1, sE-selectin, insulin, $\mathrm{HbA}_{1 \mathrm{c}}$, C-peptide, proinsulin, and ferritin had been run previously and are described in detail elsewhere $(16,20-22)$. 


\section{Assessment of lifestyle exposures}

Body weight, BMI, lifestyle, and medical history variables were determined as previously described (23). Waistto-hip ratio was determined using self-reported waist and hip circumference information in 1986 (24). Physical activity was computed as metabolic equivalent tasks (METs) per week from data on duration and intensity of exercise collected during the period 1986-2000 (16). The validity of self-reported Nurses' Health Study data has been previously reported $(23,24)$.

\section{Statistical analysis}

Descriptive characteristics were compared across quartiles of resistin levels using one-way ANOVA for continuous variables and $\chi^{2}$ tests for categorical variables. To evaluate the relationships between biomarkers, Spearman's correlations $(r)$ were performed. Multivariate linear regression analyses were then performed to adjust for age (continuous), diabetes status (yes, no), BMI (continuous), smoking (never, past, and current), alcohol intake (0.0, 0.1-4.9, 5.0-9.9, 10.0-14.9, and $\geq 15.0 \mathrm{~g} /$ day $)$, physical activity $(<3,3-8,9-17$, $18+$ METs/week), fasting status $(<8$ or $\geq 8 \mathrm{~h}$ since last meal), postmenopausal status, postmenopausal hormone use, aspirin use, history of high blood pressure, history of high blood cholesterol, and additionally for sTNF- $\alpha$ RII, IL-6, CRP, sE-selectin, sICAM-1, sVCAM-1, and ferritin. Since results were similar for log-transformed and non-transformed biomarkers and parameter estimates from nontransformed markers were more meaningful for interpretation, we only presented nontransformed results in the current analysis. Additional analysis was also conducted among the subgroup of those who remained free of type 2 diabetes. All statistical analyses were performed using SAS statistical software version 9.0 (SAS Institute, Inc., Cary, NC, USA). A study with 489 subjects would have an $80 \%$ power to detect associations with $r \geq 0.11$ at the conventional $\alpha=0.05$ level, whereas a study with 1065 subjects would have similar power to detect associations with $r \geq 0.08$.

\section{Role of funding source}

The National Institute of Health provided funding for this study. The funding source had no role in the collection, analysis or interpretation of the data, or the decision to submit the manuscript for publication.

Table 1 Characteristics by quartiles of resistin in 1065 women without diabetes and cardiovascular disease at baseline.

\begin{tabular}{|c|c|c|c|c|c|}
\hline \multirow[b]{2}{*}{ Variable } & \multicolumn{4}{|c|}{ Quartiles of resistin concentration } & \multirow[b]{2}{*}{$P$ value } \\
\hline & Q1 & Q2 & Q3 & Q4 & \\
\hline Resistin (ng/ml) & $n=266$ & $n=266$ & $n=267$ & $n=266$ & \\
\hline Range & $2.25-11.73$ & $11.73-14.93$ & $14.93-20.97$ & $20.97-99.36$ & \\
\hline \multicolumn{6}{|l|}{ Biomarkers } \\
\hline Adiponectin $(\mu \mathrm{g} / \mathrm{ml})$ & $16.3 \pm 8.3$ & $14.8 \pm 7.4$ & $14.0 \pm 7.4$ & $13.8 \pm 7.4$ & 0.0004 \\
\hline HMW adiponectin $(\mu \mathrm{g} / \mathrm{ml})$ & $6.97 \pm 5.54$ & $5.75 \pm 4.23$ & $5.38 \pm 4.43$ & $5.33 \pm 4.31$ & $<0.0001$ \\
\hline CRP (mg/dl) & $0.32 \pm 0.44$ & $0.35 \pm 0.36$ & $0.42 \pm 0.42$ & $0.52 \pm 0.59$ & $<0.0001$ \\
\hline Interleukin-6 (ng/ml) & $2.32 \pm 2.16$ & $2.56 \pm 2.49$ & $2.83 \pm 2.12$ & $3.39 \pm 3.34$ & $<0.0001$ \\
\hline sTNF- $\alpha$ RII $(\mathrm{pg} / \mathrm{ml})^{\prime}$ & $2424.0 \pm 767.4$ & $2577.6 \pm 799.9$ & $2674.7 \pm 853.9$ & $2944.0 \pm 974.6$ & $<0.0001$ \\
\hline sE-selectin (ng/ml) & $53.4 \pm 28.3$ & $57.4 \pm 30.7$ & $57.6 \pm 24.6$ & $63.0 \pm 30.0$ & 0.002 \\
\hline sICAM-1 (ng/ml) & $262.0 \pm 74.3$ & $268.2 \pm 100.3$ & $279.2 \pm 97.5$ & $278.1 \pm 69.6$ & 0.06 \\
\hline sVCAM-1 (ng/ml) & $550.2 \pm 149.9$ & $565.4 \pm 259.3$ & $575.9 \pm 154.4$ & $578.0 \pm 169.3$ & 0.30 \\
\hline Ferritin (ng/ml) & $91.1 \pm 87.2$ & $96.4 \pm 89.8$ & $81.7 \pm 79.4$ & $91.7 \pm 88.3$ & 0.26 \\
\hline Insulin $(\mu \mathrm{U} / \mathrm{ml})$ & $11.4 \pm 6.8$ & $13.0 \pm 9.6$ & $12.1 \pm 8.5$ & $12.4 \pm 7.4$ & 0.36 \\
\hline Proinsulin (fmol/ml) & $16.7 \pm 15.5$ & $19.8 \pm 17.9$ & $16.0 \pm 16.3$ & $26.5 \pm 22.2$ & 0.005 \\
\hline C-peptide (pmol/ml) & $0.69 \pm 0.55$ & $0.84 \pm 0.75$ & $0.73 \pm 0.41$ & $0.92 \pm 0.58$ & 0.04 \\
\hline $\mathrm{HbA1c}(\mathrm{g} / \mathrm{dl})$ & $0.59 \pm 0.22$ & $0.59 \pm 0.20$ & $0.57 \pm 0.18$ & $0.60 \pm 0.19$ & 0.55 \\
\hline \multicolumn{6}{|l|}{ Descriptive variables } \\
\hline Age (year) & $57.9 \pm 6.6$ & $56.9 \pm 6.7$ & $56.5 \pm 6.9$ & $56.6 \pm 7.0$ & 0.07 \\
\hline $\mathrm{BMI}$ & $26.7 \pm 5.4$ & $28.4 \pm 5.8$ & $29.1 \pm 6.1$ & $30.2 \pm 6.7$ & $<0.0001$ \\
\hline Physical activity (METs/week) & $14.7 \pm 16.7$ & $15.5 \pm 38.6$ & $13.4 \pm 16.5$ & $13.6 \pm 18.8$ & 0.74 \\
\hline Alcohol (g/day) & $5.9 \pm 11.6$ & $4.1 \pm 7.8$ & $3.6 \pm 6.7$ & $3.8 \pm 7.8$ & 0.007 \\
\hline Current smoker, $n(\%)$ & $28(10.5)$ & $23(8.7)$ & $38(\overline{14} .2)$ & $52(\overline{19} .6)$ & 0.0009 \\
\hline Fasting $(\geq 8 \mathrm{~h}), n(\%)$ & $184(69.2)$ & $197(74.1)$ & $171(64.0)$ & 170 (63.9) & 0.04 \\
\hline Postmenopausal, $n(\%)$ & $213(80.1)$ & 195 (73.3) & $187(70.0)$ & $191(71.8)$ & 0.05 \\
\hline $\begin{array}{l}\text { Current postmenopausal hormone } \\
\text { use, } n(\%)\end{array}$ & $81(30.5)$ & $68(25.6)$ & $68(25.5)$ & $64(24.1)$ & 0.36 \\
\hline Current aspirin use, $n(\%)$ & $143(53.8)$ & $114(42.9)$ & $111(41.6)$ & $114(42.9)$ & 0.02 \\
\hline History of high blood pressure & $100(37.6)$ & 119 (44.7) & $111(41.6)$ & $120(45.1)$ & 0.26 \\
\hline History of high cholesterol & $123(46.2)$ & $115(43.2)$ & $108(40.5)$ & 119 (44.7) & 0.58 \\
\hline
\end{tabular}

Values shown are mean \pm s.D. for continuous variables and frequency (percentage) for categorical variables. 


\section{Results}

In this cross-sectional study of 1065 women who were free of diabetes and CVD at blood draw, resistin levels were significantly and positively associated with BMI $(P<0.0001)$ and smoking $(P=0.0009)$, inversely associated with alcohol consumption $(P=0.007)$, and inversely but marginally associated with age $(P=0.07$; Table 1). Women with lower resistin levels were more likely to be in fasting status $(P=0.04)$, postmenopausal $(P=0.05)$, and taking aspirin $(P=0.02)$, and these factors were adjusted for in the analysis, as shown in Table 2. Resistin levels were not associated with physical activity, postmenopausal hormone use, history of high blood pressure or high cholesterol. Resistin levels were significantly and inversely associated with total $(P=$ $0.0004)$ and HMW adiponectin $(P<0.0001)$, and positively associated with CRP $(P<0.0001)$, IL-6 $(P<0.0001)$, sTNF- $\alpha$ RII $(P<0.0001)$, sE-selectin $(P=$ $0.002)$, proinsulin $(P=0.005)$, and $C$-peptide $(P=0.04)$. Resistin was not associated with sICAM-1, sVCAM-1, ferritin, insulin, and HbAlc in this crude analysis.

Table 2 Parameter estimates and $P$ values for 10 unit increase in adipokine levels in relation to biomarkers in 1065 women.

\begin{tabular}{|c|c|c|c|c|c|c|c|c|c|}
\hline \multirow[b]{2}{*}{ Biomarkers } & \multirow[b]{2}{*}{$n$} & \multicolumn{2}{|c|}{ Model $1^{a}$} & \multicolumn{2}{|c|}{ Model $2^{b}$} & \multicolumn{2}{|c|}{ Model $3^{c}$} & \multicolumn{2}{|c|}{ Model $4^{d}$} \\
\hline & & Estimate & $P$ value & Estimate & $P$ value & Estimate & $P$ value & Estimate & $P$ value \\
\hline \multicolumn{10}{|c|}{$\beta$ estimates and $P$ values for $10 \mu \mathrm{g} / \mathrm{ml}$ increase in adiponectin levels } \\
\hline HMW adiponectin $(\mu \mathrm{g} / \mathrm{ml})$ & 1065 & 5.28 & $<0.0001$ & 5.11 & $<0.0001$ & 5.06 & $<0.0001$ & 5.01 & $<0.0001$ \\
\hline Resistin (ng/ml) & 1065 & -1.40 & 0.004 & -0.77 & 0.13 & -0.59 & 0.27 & -0.26 & 0.62 \\
\hline sTNF- $\alpha$ RII $(\mathrm{pg} / \mathrm{ml})$ & 1065 & -141.4 & $<0.0001$ & -98.4 & 0.006 & -56.6 & 0.13 & -27.5 & 0.45 \\
\hline Interleukin-6 (ng/ml) & 1065 & -0.39 & 0.0002 & -0.27 & 0.01 & -0.25 & 0.03 & -0.04 & 0.72 \\
\hline $\mathrm{CRP}(\mathrm{mg} / \mathrm{dl})$ & 1065 & -0.14 & $<0.0001$ & -0.09 & $<0.0001$ & -0.09 & $<0.0001$ & -0.06 & 0.0008 \\
\hline sE-selectin (ng/ml) & 1065 & -10.9 & $<0.0001$ & -8.0 & $<0.0001$ & -7.2 & $<0.0001$ & -5.6 & $<0.0001$ \\
\hline sICAM-1 (ng/ml) & 1065 & -16.5 & $<0.0001$ & -14.0 & 0.0001 & -10.2 & 0.005 & -3.08 & 0.29 \\
\hline sVCAM-1 $(\mathrm{ng} / \mathrm{ml})$ & 1065 & -0.48 & 0.95 & 4.94 & 0.53 & 13.3 & 0.10 & 35.3 & $<0.0001$ \\
\hline Ferritin (ng/ml) & 1065 & -11.6 & 0.0007 & -13.0 & 0.0002 & -12.2 & 0.0007 & -5.84 & 0.11 \\
\hline Insulin $(\mu \mathrm{U} / \mathrm{ml})$ & 606 & -3.48 & $<0.0001$ & -2.69 & $<0.0001$ & -2.52 & $<0.0001$ & -1.76 & $<0.0001$ \\
\hline Proinsulin (fmol/ml) & 293 & -9.68 & $<0.0001$ & -8.0 & $<0.0001$ & -7.24 & $<0.0001$ & -4.53 & 0.0006 \\
\hline C-peptide (pmol/ml) & 417 & -0.28 & $<0.0001$ & -0.21 & $<0.0001$ & -0.20 & $<0.0001$ & -0.13 & 0.0004 \\
\hline $\mathrm{HbA1c}(\mathrm{g} / \mathrm{dl})$ & 631 & -0.08 & $<0.0001$ & -0.07 & $<0.0001$ & -0.07 & $<0.0001$ & -0.05 & $<0.0001$ \\
\hline \multicolumn{10}{|c|}{$\beta$ estimates and $P$ values for $10 \mu \mathrm{g} / \mathrm{ml}$ increase in $\mathrm{HMW}$ adiponectin levels } \\
\hline Total adiponectin $(\mu \mathrm{g} / \mathrm{ml})$ & 1065 & 14.2 & $<0.0001$ & 14.0 & $<0.0001$ & 13.8 & $<0.0001$ & 13.6 & $<0.0001$ \\
\hline Resistin (ng/ml) & 1065 & -2.22 & 0.005 & -1.10 & 0.19 & -0.75 & 0.39 & -0.22 & 0.80 \\
\hline sTNF- $\alpha \mathrm{RII}(\mathrm{pg} / \mathrm{ml})$ & 1065 & -210.1 & 0.0002 & -123.0 & 0.04 & -46.9 & 0.44 & -31.3 & 0.60 \\
\hline Interleukin-6 (ng/ml) & 1065 & -0.66 & 0.0001 & -0.44 & 0.01 & -0.39 & 0.04 & -013 & 0.46 \\
\hline CRP (mg/dl) & 1065 & -0.22 & $<0.0001$ & -0.13 & $<0.0001$ & -0.13 & $<0.0001$ & -0.09 & 0.005 \\
\hline $\mathrm{sE}$-selectin ( $\mathrm{ng} / \mathrm{ml})$ & 1065 & -17.1 & $<0.0001$ & -11.8 & $<0.0001$ & -10.4 & $<0.0001$ & -9.5 & $<0.0001$ \\
\hline sICAM-1 (ng/ml) & 1065 & -20.4 & 0.0003 & -14.6 & 0.02 & -7.0 & 0.25 & 0.34 & 0.94 \\
\hline sVCAM-1 $(\mathrm{ng} / \mathrm{ml})$ & 1065 & 10.7 & 0.38 & 23.6 & 0.07 & 38.4 & 0.004 & 68.6 & $<0.0001$ \\
\hline Ferritin (ng/ml) & 1065 & -16.3 & 0.004 & -17.2 & 0.003 & -15.8 & 0.008 & -66.3 & 0.27 \\
\hline Insulin $(\mu \mathrm{U} / \mathrm{ml})$ & 606 & -5.42 & $<0.0001$ & -3.91 & $<0.0001$ & -3.69 & $<0.0001$ & -2.56 & 0.001 \\
\hline Proinsulin (fmol/ml) & 293 & -17.6 & $<0.0001$ & -13.4 & $<0.0001$ & -11.7 & $<0.0001$ & -6.85 & 0.01 \\
\hline C-peptide (pmol/ml) & 417 & -0.43 & $<0.0001$ & -0.28 & $<0.0001$ & -0.25 & 0.0002 & -0.17 & 0.01 \\
\hline $\mathrm{HbA1c}(\mathrm{g} / \mathrm{dl})$ & 631 & -0.10 & $<0.0001$ & -0.09 & $<0.0001$ & -0.08 & $<0.0001$ & -0.05 & 0.003 \\
\hline \multicolumn{10}{|c|}{$\beta$ estimates and $P$ values for $10 \mathrm{ng} / \mathrm{ml}$ increase in resistin levels } \\
\hline Total adiponectin $(\mu \mathrm{g} / \mathrm{ml})$ & 1065 & -0.57 & 0.004 & -0.28 & 0.13 & -0.20 & 0.27 & -0.09 & 0.62 \\
\hline HMW adiponectin $(\mu \mathrm{g} / \mathrm{ml})$ & 1065 & -0.34 & 0.005 & -0.15 & 0.19 & -0.09 & 0.39 & -0.03 & 0.80 \\
\hline $\mathrm{sTNF}-\alpha \mathrm{RII}(\mathrm{pg} / \mathrm{ml})$ & 1065 & 138.9 & $<0.0001$ & 123.8 & $<0.0001$ & 117.7 & $<0.0001$ & 103.3 & $<0.0001$ \\
\hline Interleukin-6 (ng/ml) & 1065 & 0.38 & $<0.0001$ & 0.34 & $<0.0001$ & 0.33 & $<0.0001$ & 0.25 & $<0.0001$ \\
\hline CRP (mg/dl) & 1065 & 0.05 & $<0.0001$ & 0.03 & 0.007 & 0.03 & 0.009 & 0.01 & 0.38 \\
\hline sE-selectin (ng/ml) & 1065 & 1.89 & 0.01 & 0.90 & 0.20 & 0.84 & 0.22 & 0.45 & 0.44 \\
\hline sICAM-1 (ng/ml) & 1065 & 2.28 & 0.30 & 1.09 & 0.62 & -0.0003 & 0.99 & -3.27 & 0.05 \\
\hline sVCAM-1 $(\mathrm{ng} / \mathrm{ml})$ & 1065 & 3.74 & 0.44 & 2.07 & 0.67 & 2.37 & 0.62 & -1.94 & 0.62 \\
\hline Ferritin (ng/ml) & 1065 & 1.41 & 0.52 & 0.77 & 0.72 & 1.02 & 0.63 & 0.07 & 0.97 \\
\hline Insulin $(\mu \mathrm{U} / \mathrm{ml})$ & 606 & 0.23 & 0.44 & -0.19 & 0.53 & -0.25 & 0.40 & -0.42 & 0.14 \\
\hline Proir & 293 & 2.75 & 0.010 & 1.49 & 0.16 & 1.11 & 0.29 & 0.95 & 0.31 \\
\hline C-peptide (pmol/ml) & 417 & 0.05 & 0.10 & -0.002 & 0.92 & -0.01 & 0.76 & -0.01 & 0.56 \\
\hline $\mathrm{HbA1c}(\mathrm{g} / \mathrm{dl})$ & 631 & 0.01 & 0.10 & 0.004 & 0.51 & 0.003 & 0.62 & 0.005 & 0.46 \\
\hline
\end{tabular}

aUnadjusted.

${ }^{\mathrm{b}}$ Adjusted for age and BMI.

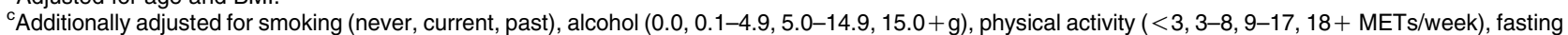
$(\mathrm{Y} / \mathrm{N})$, postmenopausal status $(\mathrm{Y} / \mathrm{N})$, postmenopausal hormone usage $(\mathrm{Y} / \mathrm{N})$, aspirin usage $(\mathrm{Y} / \mathrm{N})$, history of hypertension, and history of hypercholesterolemia $(\mathrm{Y} / \mathrm{N})$.

${ }^{d}$ Additionally adjusted for sTNF- $\alpha$ RII, IL-6, CRP, sE-selectin, sICAM-1, sVCAM-1, and ferritin. 


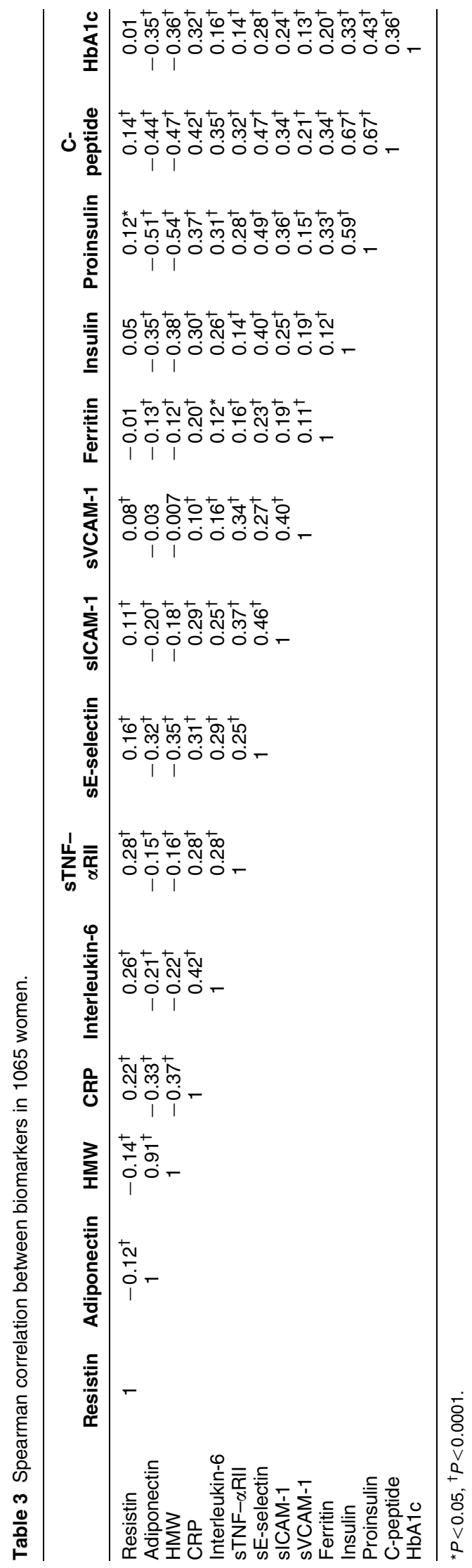

Spearman's correlation analyses generated similar results (Table 3). Resistin was significantly positively correlated with CRP $(r=0.22)$, IL-6 $(r=0.26)$, sTNF$\alpha \mathrm{RII}(r=0.28)$, and sE-selectin $(r=0.16)$ at $P<0.0001$, and with sICAM-1 $(r=0.11)$, sVCAM-1 $(r=0.08)$, proinsulin $(r=0.12)$, and C-peptide $(r=0.14)$ at $P<0.05$. Resistin was also significantly inversely correlated with total $(r=-0.12)$ and HMW $(r=-0.14)$ adiponectin $(P<0.0001$ for both). Resistin was not correlated with ferritin, insulin, or $\mathrm{HbAlc}$. Total and HMW adiponectin were both significantly inversely correlated with biomarkers of inflammation, endothelial function, and insulinemia or insulin resistance/secretion, with the sole exception of sVCAM-1.

Multivariate analyses showed that resistin was significantly positively associated with sTNF- $\alpha$ RII and IL-6 $(P<0.0001)$, and was not associated with CRP, sE-selectin, sICAM-1, sVCAM-1, or ferritin, controlling for confounding effects from all anthropometric and inflammatory parameters (Table 2, Model 4). For each $10 \mathrm{ng} / \mathrm{ml}$ of increase in resistin level, sTNF- $\alpha \mathrm{RII}$ increases by $103.3 \mathrm{pg} / \mathrm{ml}(P<0.0001)$ and IL-6 increases by $0.25 \mathrm{ng} / \mathrm{ml}(P<0.0001)$. Among all anthropometric parameters, age and BMI were the most significant confounders on the relationships between resistin and inflammatory markers; the parameter estimates and $P$ values of sTNF- $\alpha$ RII, IL- 6 , and CRP did not change substantially when all anthropometric parameters were introduced in Model 3 , in addition to age and BMI in Model 2. When all inflammatory markers were controlled for in Model 4, the associations between resistin, sTNF- $\alpha$ RII, and IL- 6 decreased in magnitude but remained highly significant $(P<0.0001)$, and the association between resistin and CRP became insignificant. Secondary analyses on insulin, proinsulin, C-peptide, and $\mathrm{HbA} 1 \mathrm{c}$ showed that resistin was not associated with any of these four biomarkers. Controlling for confounding from all anthropometric factors and inflammatory markers did not change these results.

There were statistically significant inverse associations between total adiponectin levels and sE-selectin, insulin, proinsulin, and C-peptide in both crude and multivariate analysis (Table 2). Total adiponectin was not significantly associated with sVCAM-1 in crude analysis, but a significant positive association between adiponectin and SVCAM-1 was evident after adjustment for lifestyle variables and mutual adjustment for the markers of inflammation and endothelial function $(P<0.0001)$.

Associations between HMW adiponectin and the other biomarkers were very similar to those of total adiponectin. HMW adiponectin was significantly associated with sE-selectin, insulin, and sVCAM-1 after adjustment for possible confounders in multivariate analysis (Table 2). As seen with total adiponectin, a positive relationship between HMW adiponectin and sVCAM-1 became significant after multivariate 
adjustment. Both total and HMW adiponectin were inversely associated with HbA1c (Table 2).

Additional analysis conducted among the women who did not develop diabetes later in life produced similar results, and thus, only results from the entire cohort are presented herein. No notable effect modification was detected for obesity, fasting, or $\mathrm{HbAlc}$ levels.

\section{Discussion}

Resistin is derived almost exclusively from adipose tissue in rodents (25), but in contrast to rodents, resistin is expressed primarily in inflammatory cells, especially macrophages (26), in humans. Although resistin mRNA is detectable in human adipocytes (27), expression levels are much higher in human inflammatory cells $(26,28)$. Similar to a previous study in healthy men and women with a family history of coronary artery disease (29), we detected significant associations between resistin and sTNF- $\alpha$ RII, IL-6, and CRP, inflammatory markers derived mainly from monocytes and vascular endothelium rather than adipocytes. Resistin levels have previously been reported to be associated with plasma CRP levels in healthy men and women, as well as patients with coronary artery disease or diabetes, or patients at high risk for diabetes (19, 30-33). In diabetics, the magnitude of the previously reported associations is similar to the associations in healthy women reported herein. In this cohort of women, however, the relationship between resistin and CRP was attenuated after adjustment for the other biomarkers of inflammation and endothelial function studied. This suggests that the previously observed association between resistin and CRP may be mediated in part by the positive relationships between resistin, sTNF- $\alpha$ RII, and IL- 6 , both of which are upstream of CRP, the levels of which depend on sTNFaRII and IL-6 activity. Laboratory investigations have demonstrated that inflammatory responses may stimulate resistin secretion $(28,34,35)$. Conversely, resistin may also promote production of proinflammatory mediators such as IL- 6 and sTNF- $\alpha$ RII, in part by activation of the nuclear receptor factor $\kappa$-B signaling pathway (36). Data in this study are consistent with those prior laboratory investigations but cannot prove causality and/or direction of association given the cross-sectional nature of the study.

In healthy women, adiponectin levels are significantly and inversely associated with plasma CRP, a marker of systemic inflammation induced by proinflammatory cytokines in the liver (37). Adiponectin has been shown to be inversely associated with CRP concentrations in recent cross-sectional studies among patients with type 2 diabetes (38), patients who are diabetic or at risk for diabetes (19), patients with vascular disease or dyslipidemia (39), and among apparently healthy men (40) but this is the first study in women. In addition, significant inverse associations between adiponectin and plasma sE-selectin concentrations are shown herein and remain significant after multivariate analysis. This finding confirms the inverse relationship seen previously in a cross-sectional investigation of 62 patients with coronary heart disease (41). We also reported that adiponectin is significantly positively associated with sVCAM-1 after multivariate adjustment, similar to a recent cross-sectional study among 264 patients with vascular disease or dyslipidemia (39). This association has been attributed to a possible involvement of adiponectin in the shedding of ectodomains of sVCAM-1 from the endothelial surface. Adiponectin may downregulate effects of sVCAM-1 (39), but the full effects of adiponectin on sVCAM-1 need to be confirmed and the underlying mechanisms need to be fully elucidated. Similar to total adiponectin, we also observed significant inverse relationships of HMW adiponectin with CRP and sE-selectin and a positive association of HMW adiponectin with sVCAM-1, which were independent of other risk factors and biomarkers of inflammatory disease. These data support a recent report that higher HMW adiponectin concentrations are associated with improved endothelial function (42). HMW adiponectin was also independently inversely associated with insulin resistance, as seen previously (8). Thus, the relationships between total and HMW adiponectin with inflammation and insulin resistance may be mediated by direct effects on CRP, sE-selectin, and biomarkers of insulin resistance. Women with higher plasma total and HMW concentrations also had significantly lower $\mathrm{HbA1c}$ levels, despite the fact that all women were healthy and within the normal range of $\mathrm{HbAlc}$. This is consistent with adiponectin's role as an insulin sensitizer, as previously proposed.

Strengths of this study include its relatively large size and the use of a well-known cohort of women with excellent validation of diabetes diagnosis (or lack thereof), and measurements of an extensive list of risk factors (including detailed information on diet and lifestyle) as well as biomarkers associated with diabetes and CVD that we could adjust for in the models. Although we have detailed information on lifestyle exposures, which allowed us to control for known CVD and diabetes risk factors in analysis, the potential for residual confounding by unknown factors cannot be eliminated. Analytes were measured using state of the art techniques but random misclassification remains a possibility. This could have attenuated effect estimates but cannot account for the significant results reported herein. We recognize several limitations of this study. We obtained only a single blood measure of adipokines, but this has shown to be a reliable indicator of more than one measurement over time and to be reflective of long-term hormone concentrations. Within-individual variability has been reported to be small for resistin and adiponectin, with correlations of 0.95 and 0.73 
respectively over 3 years (43). Biomarkers of insulinemia and insulin secretion were used in lieu of clinical measurements of insulin resistance, but the indicators used herein have been proven to be reliable predictors of insulin resistance in large epidemiology studies such as this one. Observational studies such as the one herein cannot prove causality since they report only associations. Nevertheless, the associations observed in this study were independent of the effects of confounders, including physical activity and other modifiable lifestyle factors. In addition, results of this study may not be generalizable to the entire population since the analysis was limited to healthy women only. Healthy women were the focus of the study since no studies have assessed these adipokines as predictors of risk in healthy women, who either develop or never develop diabetes later in life.

In conclusion, our observations in healthy women confirm previously reported associations of adiponectin with biomarkers of inflammation, endothelial function, and insulin resistance and secretion in other populations and further extend that the association with sE-selectin is independent of lifestyle and medical history factors as well as the other biomarkers of inflammation, endothelial function, and insulin resistance/secretion. We report for the first time that in healthy women, HMW adiponectin is also independently associated with CRP, sE-selectin, and sVCAM-1 concentrations and biomarkers of insulin resistance. We also report that there is a close association between resistin and two biomarkers of inflammation, IL- 6 and sTNF- $\alpha$ RII, but circulating resistin concentrations are not associated with biomarkers of endothelial function, insulinemia, insulin secretion, or glycemia. These findings are of both physiological and potential prognostic significance. Future prospective studies are needed to establish and/or confirm prospectively the value of these markers as predictors of risk for developing disease states associated with insulin resistance such as diabetes, CVD, and certain malignancies.

\section{Declaration of interest}

The authors declare that there is no conflict of interest that could be perceived as prejudicing the impartiality of the research reported.

\section{Funding}

This work was supported by the National Institute of Health (grants HL65582, HL60712, HL34594, DK58785, DK081923, DK79929, and DK58845), a discretionary grant from BIDMC, and a grant-in-aid by Tanita Corporation. Dr Hu is a recipient of the American Heart Association Established Investigator Award. Dr Sun is supported by a Postdoctoral Fellowship from the Unilever Corporate Research.

\section{References}

1 Chan J \& Mantzoros C. Role of leptin in energy-deprivation states: normal human physiology and clinical implications for hypothalamic amenorrhoea and anorexia nervosa. Lancet 2005 $36674-85$.
2 Kadowaki $\mathrm{T} \&$ Yamauchi T. Adiponectin and adiponectin receptors. Endocrine Reviews 200526 439-451.

3 Stefan N \& Stumvoll M. Adiponectin - its role in metabolism and beyond. Hormone and Metabolic Research 200234 469-474.

4 Yamauchi T, Kamon J, Minokoshi Y, Ito Y, Waki H, Uchida S, Yamashita S, Noda M, Kita S, Ueki K, Eto K, Akanuma Y, Froguel P, Foufelle F, Ferre P, Carling D, Kimura S, Nagai R, Kahn BB \& Kadowaki T. Adiponectin stimulates glucose utilization and fatty-acid oxidation by activating AMP-activated protein kinase. Nature Medicine 20028 1288-1295.

5 Spranger J, Kroke A, Mohlig M, Bergmann MM, Ristow M, Boeing $\mathrm{H} \&$ Pfeiffer AF. Adiponectin and protection against type 2 diabetes mellitus. Lancet $2003361226-228$.

6 Schulze MB, Shai I, Rimm EB, Li T, Rifai N \& Hu FB. Adiponectin and future coronary heart disease events among men with type 2 diabetes. Diabetes $2005 \mathbf{5 4} 534-539$.

7 Pischon T, Girman CJ, Hotamisligil GS, Rifai N, Hu FB \& Rimm EB. Plasma adiponectin levels and risk of myocardial infarction in men. Journal of the American Medical Association 2004291 $1730-1737$.

8 Hara K, Horikoshi M, Yamauchi T, Yago H, Miyazaki O, Ebinuma H, Imai Y, Nagai R \& Kadowaki T. Measurement of the high-molecular weight form of adiponectin in plasma is useful for the prediction of insulin resistance and metabolic syndrome. Diabetes Care 200629 1357-1362.

9 Mantzoros CS, Li T, Manson JE, Meigs JB \& Hu FB. Circulating adiponectin levels are associated with better glycemic control, more favorable lipid profile, and reduced inflammation in women with type 2 diabetes. Journal of Clinical Endocrinology and Metabolism $2005904542-4548$.

10 Rajala MW, Obici S, Scherer PE \& Rossetti L. Adipose-derived resistin and gut-derived resistin-like molecule-beta selectively impair insulin action on glucose production. Journal of Clinical Investigation $2003111225-230$.

11 Savage DB, Sewter CP, Klenk ES, Segal DG, Vidal-Puig A, Considine RV \& O'Rahilly S. Resistin/Fizz3 expression in relation to obesity and peroxisome proliferator-activated receptor-gamma action in humans. Diabetes 200150 2199-2202.

12 Lee JH, Chan JL, Yiannakouris N, Kontogianni M, Estrada E, Seip R, Orlova C \& Mantzoros CS. Circulating resistin levels are not associated with obesity or insulin resistance in humans and are not regulated by fasting or leptin administration: cross-sectional and interventional studies in normal, insulin-resistant, and diabetic subjects. Journal of Clinical Endocrinology and Metabolism $2003 \mathbf{8 8} 4848-4856$.

13 Kawanami D, Maemura K, Takeda N, Harada T, Nojiri T, Imai Y, Manabe I, Utsunomiya K \& Nagai R. Direct reciprocal effects of resistin and adiponectin on vascular endothelial cells: a new insight into adipocytokine-endothelial cell interactions. Biochemical and Biophysical Research Communications 2004314 415-419.

14 Verma S, Li SH, Wang CH, Fedak PW, Li RK, Weisel RD \& Mickle DA. Resistin promotes endothelial cell activation: further evidence of adipokine-endothelial interaction. Circulation 2003 108 736-740.

15 Libby P. Inflammation in atherosclerosis. Nature $2002 \mathbf{4 2 0}$ 868-874.

$16 \mathrm{Hu} \mathrm{FB}$, Meigs JB, Li TY, Rifai N \& Manson JE. Inflammatory markers and risk of developing type 2 diabetes in women. Diabetes 200453 693-700.

17 Bluher M, Brennan AM, Kelesidis T, Kratzsch J, Fasshauer M, Kralisch S, Williams CJ \& Mantzoros CS. Total and high-molecular weight adiponectin in relation to metabolic variables at baseline and in response to an exercise treatment program: comparative evaluation of three assays. Diabetes Care $200730280-285$.

18 Mantzoros CS, Williams CJ, Manson JE, Meigs JB \& Hu FB. Adherence to the Mediterranean dietary pattern is positively associated with plasma adiponectin concentrations in diabetic women. American Journal of Clinical Nutrition 200684 328-335.

19 Shetty GK, Economides PA, Horton ES, Mantzoros CS \& Veves A. Circulating adiponectin and resistin levels in relation to metabolic 
factors, inflammatory markers, and vascular reactivity in diabetic patients and subjects at risk for diabetes. Diabetes Care 200427 2450-2457.

$20 \mathrm{Hu}$ FB, Doria A, Li T, Meigs JB, Liu S, Memisoglu A, Hunter D \& Manson JE. Genetic variation at the adiponectin locus and risk of type 2 diabetes in women. Diabetes 200453 209-213.

21 Jiang R, Manson JE, Meigs JB, Ma J, Rifai N \& Hu FB. Body iron stores in relation to risk of type 2 diabetes in apparently healthy women. Journal of the American Medical Association 2004291 711-717.

22 Lopez-Garcia E, Schulze MB, Fung TT, Meigs JB, Rifai N, Manson JE \& $\mathrm{Hu}$ FB. Major dietary patterns are related to plasma concentrations of markers of inflammation and endothelial dysfunction. American Journal of Clinical Nutrition $2004 \mathbf{8 0}$ 1029-1035.

23 Colditz GA, Martin P, Stampfer MJ, Willett WC, Sampson L, Rosner B, Hennekens CH \& Speizer FE. Validation of questionnaire information on risk factors and disease outcomes in a prospective cohort study of women. American Journal of Epidemiology 1986 123 894-900.

24 Rimm EB, Stampfer MJ, Colditz GA, Chute CG, Litin LB \& Willett WC. Validity of self-reported waist and hip circumferences in men and women. Epidemiology 19901 466-473.

25 Steppan CM, Bailey ST, Bhat S, Brown EJ, Banerjee RR, Wright CM, Patel HR, Ahima RS \& Lazar MA. The hormone resistin links obesity to diabetes. Nature 2001409 307-312.

26 Patel L, Buckels AC, Kinghorn IJ, Murdock PR, Holbrook JD, Plumpton C, Macphee $\mathrm{CH} \&$ Smith SA. Resistin is expressed in human macrophages and directly regulated by PPAR gamma activators. Biochemical and Biophysical Research Communications $2003300472-476$.

27 McTernan CL, McTernan PG, Harte AL, Levick PL, Barnett AH \& Kumar S. Resistin, central obesity, and type 2 diabetes. Lancet $200235946-47$.

28 Kaser S, Kaser A, Sandhofer A, Ebenbichler CF, Tilg H \& Patsch JR. Resistin messenger-RNA expression is increased by proinflammatory cytokines in vitro. Biochemical and Biophysical Research Communications 2003309 286-290.

29 Reilly MP, Lehrke M, Wolfe ML, Rohatgi A, Lazar MA \& Rader DJ. Resistin is an inflammatory marker of atherosclerosis in humans. Circulation $2005111932-939$.

30 Al-Daghri N, Chetty R, McTernan PG, Al-Rubean K, Al-Attas O, Jones AF \& Kumar S. Serum resistin is associated with C-reactive protein \& LDL cholesterol in type 2 diabetes and coronary artery disease in a Saudi population. Cardiovascular Diabetology 2005 410.

31 Bo S, Gambino R, Pagani A, Guidi S, Gentile L, Cassader M \& Pagano GF. Relationships between human serum resistin, inflammatory markers and insulin resistance. International Journal of Obesity 200529 1315-1320.
$32 \mathrm{Hu}$ WL, Qiao SB, Hou Q \& Yuan JS. Plasma resistin is increased in patients with unstable angina. Chinese Medical Journal 2007 120 871-875.

33 Reilly MP, Wolfe ML, Rhodes T, Girman C, Mehta N \& Rader DJ. Measures of insulin resistance add incremental value to the clinical diagnosis of metabolic syndrome in association with coronary atherosclerosis. Circulation 2004110 803-809.

34 Lehrke M, Reilly MP, Millington SC, Iqbal N, Rader DJ \& Lazar MA. An inflammatory cascade leading to hyperresistinemia in humans. PLoS Medicine 20041 e45.

35 Lu SC, Shieh WY, Chen CY, Hsu SC \& Chen HL. Lipopolysaccharide increases resistin gene expression in vivo and in vitro. FEBS Letters $2002530158-162$.

36 Bokarewa M, Nagaev I, Dahlberg L, Smith U \& Tarkowski A. Resistin, an adipokine with potent proinflammatory properties. Journal of Immunology $2005 \mathbf{1 7 4} 5789-5795$.

37 Blake GJ \& Ridker PM. Inflammatory bio-markers and cardiovascular risk prediction. Journal of Internal Medicine 2002252 283-294.

38 Top C, Sahan B \& Onde ME. The relationship between left ventricular mass index and insulin sensitivity, postprandial glycaemia, and fasting serum triglyceride and adiponection levels in patients with type 2 diabetes. Journal of International Medical Research 200735 909-916.

39 Vaverkova H, Karasek D, Novotny D, Jackuliakova D, Halenka M, Lukes J \& Frohlich J. Positive association of adiponectin with soluble vascular cell adhesion molecule sVCAM-1 levels in patients with vascular disease or dyslipidemia. Atherosclerosis 2008197 725-731.

40 Komatsu M, Ohfusa H, Aizawa T \& Hashizume K. Adiponectin inversely correlates with high sensitive C-reactive protein and triglycerides, but not with insulin sensitivity, in apparently healthy Japanese men. Endocrine Journal 2007 54 553-558.

41 Kowalska I, Straczkowski M, Nikolajuk A, Kinalska I, Gorska M, Prokop J, Bachorzewska-Gajewska H \& Musial W. Plasma adiponectin and E-selectin concentrations in patients with coronary heart disease and newly diagnosed disturbances of glucose metabolism. Advances in Medical Sciences 200651 94-97.

42 Torigoe M, Matsui H, Ogawa Y, Murakami H, Murakami R, Cheng XW, Numaguchi Y, Murohara T \& Okumura K. Impact of the high-molecular-weight form of adiponectin on endothelial function in healthy young men. Clinical Endocrinology 200767 276-281.

43 Kaplan RC, Ho GY, Xue X, Rajpathak S, Cushman M, Rohan TE, Strickler HD, Scherer PE \& Anastos K. Within-individual stability of obesity-related biomarkers among women. Cancer Epidemiology, Biomarkers \& Prevention 200716 1291-1293.

Received 9 October 2009

Accepted 16 November 2009 